\title{
Insufficient evidence regarding benefits from sodium-glucose cotransporter-2 inhibitors in heart failure with preserved ejection fraction
}

\author{
Tatyana A. Shamliyan', Anna A. Avanesova², Wilbert S. Aronow ${ }^{3}$ \\ ${ }^{1}$ Carvell Health Services, Inc, Cheltenham, PA 19012, USA. \\ ${ }^{2}$ North-Caucasus Federal University, Stavropol 355000, Russian Federation. \\ ${ }^{3}$ Departments of Cardiology and Medicine, Westchester Medical Center and New York Medical College, Valhalla, NY 10595, \\ USA.
}

Correspondence to: Dr. Tatyana A. Shamliyan, Carvell Health Services, Inc, Cheltenham, PA 19012, USA.

E-mail:sham1005@umn.edu

\begin{abstract}
How to cite this article: Shamliyan TA, Avanesova AA, Aronow WS. Insufficient evidence regarding benefits from sodiumglucose cotransporter-2 inhibitors in heart failure with preserved ejection fraction. Vessel P/us 2020;4:35.

http://dx.doi.org/10.20517/2574-1209.2020.34
\end{abstract}

Received: 27 Jul 2020 First Decision: 19 Oct 2020 Revised: 22 Oct 2020 Accepted: 28 Oct 2020 Published: 18 Nov 2020

Academic Editor: Ryuuichi Morishita Copy Editor: Cai-Hong Wang Production Editor: Jing Yu

\begin{abstract}
Aim: Sodium-glucose cotransporter-2 (SGLT2)-inhibitors improve survival in adults with reduced ejection fraction. Clinical outcomes in adults with heart failure (HF) with preserved ejection fraction (HFpEF) have not been systematically reviewed.
\end{abstract}

Methods: We conducted a systematic rapid literature review and appraised the quality of evidence using the Grading of Recommendations Assessment, Development and Evaluation methodology.

Results: We identified post-hoc subgroup analyses of four randomized controlled clinical trials (RCTs) and unpublished results from 2 RCTs. In 2 RCTs vs. placebo, Canagliflozin reduced the risk of fatal or hospitalized HF in adults with $\mathrm{HF}$ and documented or assumed left ventricular ejection fraction (LVEF) $\geq 50 \%$ (hazard rate ratio, HR $=0.71,95 \% \mathrm{Cl}: 0.52-0.97)$ but had no effect in a subpopulation with documented LVEF $\geq 50 \%(\mathrm{HR}=0.83,95 \% \mathrm{Cl}$ : 0.55-1.25). Dapagliflozin or ertugliflozin did not improve all-cause or cardiovascular death or hospitalization for HF in adults with HF and LVEF > 45\% in two pivotal RCTs vs. placebo. Empagliflozin did not improve exercise ability, patient-reported outcomes or congestion, diuretic use and all-cause healthcare resource utilization in unpublished RCT vs. placebo. Various definitions of HFpEF, post-hoc interaction analyses suggesting outcome improvement

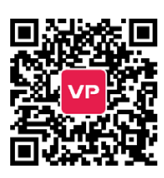


regardless of heart failure type, small number of events, and probable publication bias hampered the quality of evidence.

Conclusion: Existing evidence is insufficient to support definitive clinical recommendations for use of SGLT2inhibitors in adults with HFpEF. Future research should employ consistent definitions of HFpEF and examine the effects from SGLT2- Inhibitors in patients with various HFpEF phenotypes and underlying causes.

Keywords: Sodium-glucose cotransporter-2 - inhibitors, heart failure with preserved ejection fraction, cardiovascular mortality, heart failure hospitalization, systematic literature review, grading of recommendations assessment, development and evaluation methodology

\section{INTRODUCTION}

Heart failure with preserved ejection fraction (HFpEF) presents a significant and growing clinical and economic burden in aging populations, specifically with prevalent arterial hypertension and diabetes ${ }^{[1-4]}$. Estimated 1-year all-cause mortality rates of $33 \%$ and all cause readmission rates of $67 \%$ in patients with HFpEF have not improve over the last decade in the US ${ }^{[3]}$. Diabetes is a widely recognized risk factor for cardiovascular morbidity and mortality ${ }^{[5,6]}$. Although emerging treatments improved cardiovascular outcomes in people with diabetes ${ }^{[7,8]}$, no treatments have been proven to improve survival and reduce health care utilization in people with $\mathrm{HFpEF}^{[9-14]}$. Sodium-glucose cotransporter-2 (SGLT2)- inhibitors are found to improve survival in heart failure with reduce ejection fraction and reduce the risk of major cardiovascular events including heart failure hospitalizations in adults with type 2 diabetes ${ }^{[15-19]}$. Empagliflozin and canagliflozin have been approved by the US Food and Drug Administration (FDA) to reduce the risk of cardiovascular death in adults with type 2 diabetes and established cardiovascular disease while dapagliflozin has also been approved to reduce the risk of cardiovascular death and hospitalization for heart failure in adults with reduced left ventricular ejection fraction (LVEF $\leq 40 \%)^{[20-25]}$. Recent evidence-based guidelines recommend SGLT2- inhibitors for the improvement in cardiovascular outcomes in adults with type 2 diabetes ${ }^{[26-29]}$. However, the evidence regarding the benefits from SGLT2- inhibitors in adults with HFpEF has not been systematically reviewed and appraised. We conducted a systematic rapid literature review of all completed and ongoing clinical studies aimed at patient outcomes in adults with HFpEF.

\section{METHODS}

We conducted our review according to the developed priori protocol ${ }^{[30-32]}$. We hypothesized that SGLT2inhibitors improve cardiovascular mortality, morbidity and hospitalizations in adults with HFpEF, with or without diabetes ${ }^{[33-38]}$.

Eligible interventions included SGLT2- inhibitors regardless of country' approval [Supplementary Table 1] focusing on the availability in the US, for example dapagliflozin, canagliflozin, empagliflozin and ertugliflozin [Supplementary Table 2]. We included studies that compared SGLT2- inhibitors with antidiabetic medications or placebo. We abstracted reported number of events or rates of all-cause and cardiovascular mortality, incident or progressing of heart failure, and hospitalizations for heart failure ${ }^{[14,39]}$. We also looked at the reported intermediate outcomes, e.g., exercise tolerability and the quality of life or other patient reported outcomes as defined in the primary studies ${ }^{[40-45]}$.

We conducted a comprehensive search with MeSH terms and key words in PubMed, Scopus, the Cochrane Library, www.clinicaltrials.gov, the World Health organization International Clinical Trials Registry Platform, Health Technology Assessment databases, and regulatory agencies up to October 2020 to find 
systematic reviews, published and unpublished randomized controlled clinical trials (RCTs), and realworld evidence from the high quality nationally representative controlled observational studies ${ }^{[30,31]}$. All of the authors looked at the retrieved publications as well as the evidence-based guidelines that provided definitions of HFpEF and recommend treatments for HFpEF. We documented the eligibility of studies in a reference database.

We planned a quantitative direct meta-analysis of similar interventions and outcomes using random effects models in compliance with recommended meta-analytic methods ${ }^{[46]}$. We intended to calculate pooled relative risk, absolute risk difference, number needed to treat and number of attributable events per 1000 treated with $95 \%$ confidence intervals (CI). We proposed to examine inconsistency in treatment effects with recommended I2 statistics (if I2 was $>50 \%)^{[30]}$. We planned pooled analyses regardless of statistically significant heterogeneity ${ }^{[46]}$. Instead, we proposed exploring heterogeneity with a priori defined patient characteristics, e.g., definitions of HFpEF, outcomes, and study quality ${ }^{[46]}$.

Since post hoc analyses of statistical power is not recommended ${ }^{[47-50]}$, we downgraded the quality of evidence for imprecision based on an estimated priori optimal information size in an adequately powered RCT (e.g., $\geq 250$ patients with the event) ${ }^{[51]}$.

We concluded statistical significance at a 95\% confidence level using Statistics/Data Analysis, STATA software (StataCorp LP, College Station, Texas).

We judged the risk of bias in primary studies with the Cochrane risk of bias tool ${ }^{[52-54]}$. We judged the quality of evidence according to the recommendations by the grading of recommendations assessment, development and evaluation (GRADE) methodology ${ }^{[55]}$. We downgraded the quality of evidence from RCTs according to the domains of the risk of bias in the body of evidence, directness of comparisons, precision and consistency in treatment effects, and the probability of the reporting bias ${ }^{[55]}$. We assigned low quality of evidence to all nonrandomized studies, upgrading the quality for the evidence of a strong or dose-response association ${ }^{[56]}$. We concluded insufficient evidence when valid information about treatment effects was not identified.

\section{RESULTS}

We excluded the majority of clinical studies of SGLT2- inhibitors because they did not report patient outcomes in adults with HFpEF (search strings are available in the appendix and the list of excluded publications and registered studies is available by the request from the authors). We identified post hoc subgroup individual patient data meta-analysis of the CANVAS (Canagliflozin Cardiovascular Assessment Study) Program that examined canagliflozin when compared with placebo in patients with HFpEF [Table 1] $]^{[57]}$. We identified post-hoc subgroup analysis of the pivotal DECLARE-TIMI 58 (Dapagliflozin Effect on Cardiovascular Events-Thrombolysis in Myocardial Infarction 58) RCT that examined dapagliflozin when compared with placebo in patients with HFpEF [Table 1] ${ }^{[58]}$. We also identified unpublished results from pivotal EMPERIAL trials that examined empagliflozin when compared with placebo in patients with $\mathrm{HFpEF}^{[59-61]}$. We identified post-hoc subgroup analysis of the pivotal VERTIS CV RCT (Evaluation of Ertugliflozin Efficacy and Safety Cardiovascular Outcomes Trial) that examined ertugliflozin when compared with placebo in patients with HFpEF [Table 1 $]^{[62]}$.

We did not identify observational studies that reported patient outcomes after SGLT2- inhibitors in patients with HFpEF and concluded probable publication bias because several completed registered studies remain unpublished. We downgraded the quality of evidence for high risk of bias in post-hoc subgroup analyses, imprecision in treatment effects due to small number of events, and probable publication bias. We concluded that the evidence is insufficient for definitive clinical recommendation to use SGLT2- inhibitors 
Table 1. Sodium-glucose cotransporter 2 inhibitors in adults with heart failure with preserved ejection fraction, the results from post-hoc subgroup analyses of the randomized controlled clinical trials

\begin{tabular}{|c|c|c|}
\hline Population Definition & Outcome & Treatment effect \\
\hline \multicolumn{3}{|c|}{ 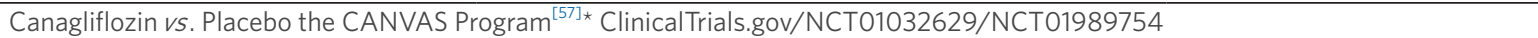 } \\
\hline $\begin{array}{l}\text { Heart failure event with documented } \\
\mathrm{EF} \text { of } \geq 50 \% \text { at the } \mathrm{HF} \text { admission }\end{array}$ & Fatal or hospitalized heart failure & HR $0.83(0.55-1.25)$ \\
\hline $\begin{array}{l}\text { Heart failure event with documented } \\
\mathrm{EF} \text { of } \geq 50 \% \text { or assumed to be } \geq 50 \%\end{array}$ & Fatal or hospitalized heart failure & HR $0.71(0.52-0.97)^{1}$ \\
\hline \multicolumn{3}{|c|}{$\begin{array}{l}\text { Dapagliflozin, } 10 \mathrm{mg} \text { vs. Placebo DECLARE-TIMI } 58 \text { (Dapagliflozin Effect on Cardiovascular Events-Thrombolysis in Myocardial } \\
\text { Infarction 58) }{ }^{[58] * \star} \text { ClinicalTrials.gov/NCT01730534 }\end{array}$} \\
\hline \multirow{4}{*}{$\begin{array}{l}\text { Heart failure with } E F \text { of } \geq 45 \% \text { or } \\
\text { without known reduced ejection } \\
\text { fraction }\end{array}$} & Cardiovascular death or hospitalization for heart failure & HR $0.88(0.66-1.17)$ \\
\hline & Hospitalization for heart failure & HR $0.72(0.5-1.04)$ \\
\hline & Cardiovascular death & HR $1.41(0.93-2.13)$ \\
\hline & All-cause mortality & HR $1.02(0.75-1.38)$ \\
\hline \multirow[t]{4}{*}{ Heart failure with $\mathrm{EF}$ of $\geq 45 \%$} & Cardiovascular death or hospitalization for heart failure & HR $0.79(0.56-1.13)$ \\
\hline & Hospitalization for heart failure & HR $0.74(0.48-1.14)$ \\
\hline & Cardiovascular death & HR $1.44(0.83-2.49)$ \\
\hline & All-cause mortality & HR $1.06(0.71-1.59)$ \\
\hline \multirow[t]{4}{*}{ Heart failure with EF $45-<55 \%$} & Cardiovascular death or hospitalization for heart failure & HR $0.83(0.58-1.2)$ \\
\hline & Hospitalization for heart failure & HR $0.76(0.48-1.19)$ \\
\hline & Cardiovascular death & HR $1.18(0.69-2.01)$ \\
\hline & All-cause mortality & HR $0.98(0.66-1.46)$ \\
\hline \multicolumn{3}{|c|}{$\begin{array}{l}\text { Ertugliflozin, } 5 \mathrm{mg}, 15 \mathrm{mg} \text { vs. Placebo (Evaluation of Ertugliflozin Efficacy and Safety Cardiovascular Outcomes Trial) } \\
\text { gov/NCT01986881 }\end{array}$} \\
\hline \multirow[t]{4}{*}{ Heart Failure with EF > 45\% } & Cardiovascular death or hospitalization for heart failure & HR $0.92(0.61-1.39)$ \\
\hline & Cardiovascular death & HR $1.08(0.64-1.8)$ \\
\hline & All-cause mortality & HR $1.01(0.66-1.56)$ \\
\hline & Hospitalization for heart failure & $\operatorname{HR} 0.70(0.39-1.26)$ \\
\hline
\end{tabular}

'Statistically significant differences at $95 \%$ confidence level. ${ }^{\star} E j e c t i o n$ fraction was assessed during retrospective secondary review of the medical record data by one of the members of the original adjudication committee who was blinded to individual participant treatment assignment; ${ }^{\star \star}$ Prospective baseline assessment of ejection fraction was conducted in all participants; ${ }^{\star \star \star}$ Ejection fraction was assessed from medical records when available. EF: ejection fraction; HR: hazard rate ratio

for the reduction in cardiovascular mortality, morbidity or heart failure hospitalizations in patients with HFpEF.

\section{Canagliflozin}

Canagliflozin did not reduce the risk of fatal or hospitalized heart failure when compared with placebo in adults with type 2 diabetes and heart failure with documented LVEF of $\geq 50 \%$ [Table 1] ${ }^{[57]}$. Canagliflozin reduced the risk of fatal or hospitalized heart failure in a subpopulation with heart failure and documented LVEF of $\geq 50 \%$ [Table 1$]^{[57]}$.

The CANVAS RCTs did not examine LVEF at baseline in enrolled adults of $\geq 30$ years of age with a history of symptomatic atherosclerotic cardiovascular disease or aged $\geq 50$ years with 2 or more risk factors for cardiovascular disease ${ }^{[44,63]}$. Post hoc subgroup analysis was based on retrospective secondary review of the medical hospitalization record data by one of the members of the original adjudication committee to identify patients with HFpEF defined as heart failure with documented LVEF of $\geq 50 \%$ (101 patients) ${ }^{[57]}$. The authors conducted a sensitivity analysis assuming that patients with unknown LVEF had HFpEF (61 patients) and found a significant protective effects from canagliflozin in this combined subpopulation ${ }^{[57]}$.

Based on post hoc interaction model and protective effects from canagliflozin in heart failure with reduced ejection fraction $(\mathrm{LVEF}<50 \%)$, the authors concluded similar canagliflozin benefits in the overall trial population $^{[57]}$. 
Canagliflozin improved diastolic function in patients with type 2 diabetes in two Japanese non-randomized controlled clinical trials ${ }^{[64,65]}$. One trial of canagliflozin in outpatients with chronic heart failure and diabetes (CANOSSA trial: prospective, open-label, add-on trial of canagliflozin for diabetes mellitus and stable chronic heart failure) enrolled $94 \%$ of patients with HFpEF (exact definition was not provided ${ }^{[65]}$. Canagliflozin improved echocardiographic parameters of diastolic function at 6 and 12 month $(P<$ $0.001)^{[65]}$. The second pilot study reported improved left ventricular diastolic function after 3 months of canagliflozin treatment although it did not specify baseline $\mathrm{HFpEF}^{[64]}$.

\section{Dapagliflozin}

Dapagliflozin did not improve all-cause or cardiovascular death or hospitalization for heart failure in adults with type 2 diabetes and HFpEF $(\operatorname{LVEF} \geq 45 \%)[\text { Table } 1]^{[58]}$.

DECLARE-TIMI 58 investigators conducted a prospective baseline assessment of ejection fraction in all enrolled patients with established atherosclerotic cardiovascular disease (ASCVD) or multiple risk factors for ASCVD and with a creatinine clearance $\geq 60 \mathrm{~mL} / \mathrm{min}^{[58]}$. The authors acknowledged the absence of universally accepted definitions of HFpEF and reported outcomes in subpopulations with various baseline LVEF thresholds ( $<45 \%, \geq 45 \%$, and $45 \%-55 \%$ ). Based on post hoc interaction model and protective effects from dapagliflozin in heart failure with reduced ejection fraction, the authors concluded similar dapagliflozin benefits in overall trial population ${ }^{[58]}$.

We identified two RCTs that examined the effects from dapagliflozin on diastolic function in adults with type 2 diabetes ${ }^{[6,67]}$. The RCT enrolling patients with heart failure reported that dapagliflozin significantly improved diastolic function in those with baseline LVEF $\geq 45 \%{ }^{[66]}$. The second RCT that enrolled patients without prior history of heart failure, reported that dapagliflozin had no effect on diastolic function when compared with placebo ${ }^{[67]}$.

Ongoing registered studies reported different definitions of HFpEF, exclusion of adults with various thresholds of reduced LVEF (e.g., $<45 \%$ or $<50 \%$ ) and various definitions of primary and secondary outcomes [Table 2]. Available protocols did not provide details on estimated statistical power and required sample size to detect statistically significant differences in primary outcomes.

\section{Empagliflozin}

Empagliflozin did not improve exercise tolerance, patient-reported outcomes related to the quality of life and patient satisfaction, congestion, diuretic use and all-cause healthcare resource utilization in adults with HFpEF enrolled in the pivotal EMPERIAL trials ${ }^{[59-61]}$. Trials enrolled adults with heart failure with or without diabetes ${ }^{[45]}$. The authors defined HFpEF as symptomatic heart failure with LVEF $>40 \%$ and elevated N-Terminal Pro-Brain Natriuretic Peptide [Table 3]. The unpublished results have been presented in the meeting of the European Society of Cardiology in June $2020^{[59,60]}$. Some positive trends in improving congestion after empagliflozin in HFpEF did not achieve statistical significance, possibly due to insufficient statistical power ${ }^{[59]}$.

The pivotal Empagliflozin Cardiovascular Outcome Event Trial in Type 2 Diabetes Mellitus Patients (EMPA-REG OUTCOME Trial) did not examine baseline ejection fraction but reported improvement in diastolic dysfunction as a possible mechanism in the observed reduced cardiovascular mortality and morbidity $^{[68]}$.

Ongoing registered studies reported different definitions of HFpEF (e.g., LVEF $\geq 40$ or $\geq 50 \%$ ), exclusion of adults with various thresholds of the reduced LVEF (e.g., $<30 \%$ or $<40 \%$ ) and various definitions of primary and secondary outcomes [Table 3]. Available protocols did not provide details on estimated statistical power and required sample size to detect statistically significant differences in primary outcomes. 
Table 2. Ongoing registered clinical trials of dapagliflozin in adults with heart failure with preserved ejection fraction

\begin{tabular}{|c|c|c|c|c|}
\hline $\begin{array}{l}\text { NCT number phase } \\
\text { enrollment }\end{array}$ & Title acronym & $\begin{array}{c}\text { Inclusion criteria defining } \\
\text { HFPEF }\end{array}$ & $\begin{array}{l}\text { Exclusion by } \\
\text { LVEF }\end{array}$ & Outcome measures \\
\hline $\begin{array}{l}\text { NCT03030235 } \\
\text { Phase: Phase } 4 \\
\text { Sample: } 320\end{array}$ & $\begin{array}{l}\text { Dapagliflozin in PRESERVED } \\
\text { Ejection Fraction Heart } \\
\text { Failure PRESERVED-HF }\end{array}$ & $\begin{array}{l}\text { Symptomatic heart failure } \\
\text { (NYHA class II-IV) } \\
\text { Left Ventricular Ejection } \\
\text { Fraction (LVEF) } \geq 45 \% \\
\text { Elevated NT-proBNP ( } \geq 225 \\
\mathrm{pg} / \mathrm{mL} \text { ) or BNP ( } \geq 75 \mathrm{pg} / \\
\mathrm{mL} \text { ). } \\
\text { For patients with permanent } \\
\text { atrial fibrillation (AF) BNP } \geq \\
100 \mathrm{pg} / \mathrm{mL} \text { or NTproBNP } \geq \\
375 \mathrm{pg} / \mathrm{mL}\end{array}$ & $\begin{array}{l}\text { Previous LVEF } \\
<45 \%\end{array}$ & $\begin{array}{l}\text { Change from baseline in: NTproBNP } \\
\text { and BNP, } \\
\text { heart failure related quality of life } \\
\text { using the Kansas City Cardiomyopathy } \\
\text { Questionnaire (KCCQ) overall } \\
\text { summary score, } \\
\text { 6-min walk test (6MWD) }\end{array}$ \\
\hline $\begin{array}{l}\text { NCT02751398 } \\
\text { Phase: Phase } 4 \\
\text { Sample: } 60\end{array}$ & $\begin{array}{l}\text { Impact of dapagliflozin on } \\
\text { diastolic dysfunction in type } \\
2 \text { diabetic patients }\end{array}$ & $\begin{array}{l}\geq \text { grade } 1 \text { diastolic function } \\
\text { (relaxation abnormality) at } \\
\text { resting echocardiography }\end{array}$ & $\begin{array}{l}\text { LV ejection } \\
\text { fraction }< \\
50 \%\end{array}$ & $\begin{array}{l}\text { Subclinical diastolic dysfunction } \\
\text { assessed by diastolic stress } \\
\text { echocardiography }\end{array}$ \\
\hline $\begin{array}{l}\text { NCT03619213 } \\
\text { JPRN- } \\
\text { JapicCTI-184157 } \\
\text { EUCTR2018- } \\
\text { O00802-46-CZ } \\
\text { PER-026-18 } \\
\text { Phase: Phase } 3 \\
\text { Sample: } 6100\end{array}$ & $\begin{array}{l}\text { Dapagliflozin evaluation } \\
\text { to improve the LIVEs of } \\
\text { patients with preserved } \\
\text { ejection fraction heart failure. } \\
\text { DELIVER }\end{array}$ & $\begin{array}{l}\text { Symptomatic heart failure } \\
\text { (NYHA class II-IV) } \\
\text { LVEF }>40 \% \text { and evidence } \\
\text { of structural heart disease } \\
\text { Elevated NT-pro BNP levels }\end{array}$ & NR & $\begin{array}{l}\text { The first occurrence of any of the } \\
\text { components of this composite: (1) CV } \\
\text { death; (2) Hospitalization for HF; (3) } \\
\text { Urgent HF visit } \\
\text { Total number of hospitalizations for HF } \\
\text { and CV death; } \\
\text { Change from baseline in KCCQ-TSS; } \\
\text { All-cause mortality }\end{array}$ \\
\hline $\begin{array}{l}\text { NCT03877224 } \\
\text { EUCTR2018- } \\
\text { O03441-42-DK } \\
\text { JPRN- } \\
\text { JapicCTI-194724 } \\
\text { Phase: Phase } 3 \\
\text { Sample: } 500\end{array}$ & $\begin{array}{l}\text { DETERMINE-preserved } \\
\text { - Dapagliflozin Effect on } \\
\text { Exercise Capacity using a } \\
\text { 6-min walk test in patients } \\
\text { with heart failure with } \\
\text { preserved ejection fraction }\end{array}$ & $\begin{array}{l}\text { Symptomatic heart failure } \\
\text { (NYHA functional class } \\
\text { II-IV) LVEF }>40 \% \text { and } \\
\text { evidence of structural heart } \\
\text { disease Elevated NT-proBNP } \\
\text { levels } 6 \text { MWD } \geq 100 \text { meters } \\
\text { and M } 425 \text { meters }\end{array}$ & NR & $\begin{array}{l}\text { Change from baseline in: } \\
6 M W D, \\
\text { KCCQ-TSS, } \\
\text { movement intensity during walking }\end{array}$ \\
\hline $\begin{array}{l}\text { NCT03794518 } \\
\text { Phase: Phase } 3 \\
\text { Sample: } 648\end{array}$ & $\begin{array}{l}\text { Effect of Dapagliflozin } \\
\text { plus low dose pioglitazone } \\
\text { on hospitalization rate in } \\
\text { patients with hF and HFpEF }\end{array}$ & $\begin{array}{l}\text { Hospitalized for HFpEF } \\
\text { (hospitalization require } \\
\text { intravenous diuresis) in } \\
\text { the } 6 \text { months preceding } \\
\text { recruitment. LVEF > } \\
50 \% \text { Presence of LV } \\
\text { diastolic dysfunction in } \\
\text { echocardiography }\end{array}$ & LVEF $<50 \%$ & $\begin{array}{l}\text { Time to first hospitalization for heart } \\
\text { failure after starting intervention; } \\
\text { All-cause mortality }\end{array}$ \\
\hline $\begin{array}{l}\text { JPRN- } \\
\text { UMINO00038380 } \\
\text { Sample: NR }\end{array}$ & $\begin{array}{l}\text { Yokohama add-on inhibitory } \\
\text { efficacy of dapagliflozin } \\
\text { on left ventricular filling } \\
\text { pressure in patients with } \\
\text { acute heart failure with } \\
\text { preserved ejection fraction } \\
\text { complicated with type } 2 \\
\text { diabetes study }\end{array}$ & $\begin{array}{l}\text { Acute hear failure with } \\
\text { LVEF } \geq 40 \% \text { and stable } \\
\text { hemodynamically }\end{array}$ & NR & $\begin{array}{l}\text { Change from baseline in: diastolic } \\
\text { parameters of echocardiography, } \\
\text { BNP; } \\
\text { CVD events, not specified }\end{array}$ \\
\hline
\end{tabular}

BNP: brain natriuretic peptide; NT-proBNP: N-terminal pro b-type natriuretic peptide

\section{Ertugliflozin}

The ongoing evaluation of ERTugliflozin efflcacy and Safety CardioVascular outcomes trial (VERTIS-CV) enrolled adults with type 2 diabetes and established atherosclerotic cardiovascular disease, did not specify subgroup analysis depending on baseline ejection fraction obtained from medical records but reported that $80.6 \%$ of 8,238 randomized patients had HFpEF (LVEF $>40 \%)^{[69]}$. This RCT was designed to determine non-inferiority of ertugliflozin when compared with placebo on major adverse CV events including death, nonfatal myocardial infarction, or nonfatal stroke ${ }^{[69]}$. Preliminary publications defined HFpEF as LVEF > $45 \%$ and reported no reduction in patient outcomes in this subpopulation after comparing ertugliflozin $v s$. placebo [Table 1]. Based on the post hoc interaction model and protective effects from ertugliflozin in heart failure with reduced ejection fraction, the authors concluded similar ertugliflozin benefits in the overall trial population ${ }^{[62,70]}$. 
Table 3. Ongoing registered clinical trials of empagliflozin in adults with heart failure with preserved ejection fraction

\begin{tabular}{|c|c|c|c|}
\hline $\begin{array}{l}\text { NCT number phase } \\
\text { enrollment }\end{array}$ & Title acronym & $\begin{array}{c}\text { Inclusion criteria defining } \\
\text { HFPEF }\end{array}$ & $\begin{array}{c}\text { Exclusion by } \\
\text { LVEF }\end{array}$ \\
\hline $\begin{array}{l}\text { NCT02932436 } \\
\text { Phase: Phase } 4 \\
\text { Sample: } 158\end{array}$ & $\begin{array}{l}\text { Effects of Empagliflozin on } \\
\text { left ventricular diastolic } \\
\text { function compared to usual } \\
\text { care in type } 2 \text { diabetics } \\
\text { EmDia }\end{array}$ & $\begin{array}{l}\text { Diastolic cardiac } \\
\text { dysfunction } E / E^{\prime} \text { ratio } \geq 8\end{array}$ & $\begin{array}{l}\text { NYHA } \\
\text { classification III } \\
\text { IV }\end{array}$ \\
\hline $\begin{array}{l}\text { NCT03057951 } \\
\text { EUCTR2016-002278- } \\
\text { 11-DE } \\
\text { Phase: Phase } 3 \\
\text { Sample: } 5750\end{array}$ & $\begin{array}{l}\text { Empagliflozin outcome } \\
\text { trial in patients with } \\
\text { chronic heart failure with } \\
\text { preserved ejection fraction } \\
\text { (EMPEROR-Preserved) }\end{array}$ & $\begin{array}{l}\text { Symptomatic heart failure } \\
\text { (NYHA class II-IV) } \\
\text { LVEF > } 40 \% \text { NT-proBNP } \\
>300 \text { pg/ml for patients } \\
\text { without AF, OR > } 900 \mathrm{pg} / \\
\text { ml for patients with AF }\end{array}$ & NR \\
\hline $\begin{array}{l}\text { NCT03448406 } \\
\text { Phase: phase } 3 \\
\text { sample: } 315\end{array}$ & $\begin{array}{l}\text { Empagliflozin in Patients } \\
\text { with chronic heart failure } \\
\text { with preserved ejection } \\
\text { fraction (HFpEF) } \\
\text { EMPERIAL-preserved }\end{array}$ & $\begin{array}{l}6 \mathrm{MWT} \text { M } 350 \mathrm{~m} \\
\text { Symptomatic heart failure } \\
\text { (NYHA class II-IV) } \\
\text { LVEF > } 40 \% \\
\text { NT-proBNP > } 300 \mathrm{pg} / \mathrm{ml} \\
\text { for patients without AF, OR } \\
>600 \mathrm{pg} / \mathrm{ml} \text { for patients } \\
\text { with AF }\end{array}$ & $\begin{array}{l}\text { Prior LVEF M } \\
40 \%\end{array}$ \\
\hline
\end{tabular}

\section{NCT02998970 \\ Phase: Phase 4 \\ Sample: 97}

NCT03753087

Phase: Phase 4

Sample: 100

NCT03332212

Sample: NR
Effects of Empagliflozin on cardiac structure in patients with type 2 diabetes EMPA-HEART

Effects of Empagliflozin on exercise capacity and left ventricular diastolic function in patients with heart failure with preserved ejection fraction LV diastolic dysfunction and Type-2 diabetes mellitus

EMPA-VISION: A

randomised, doubleblind, placebo-controlled, mechanistic cardiac magnetic resonance study patient without AF or NTto investigate the effects pro-BNP $>600 \mathrm{pg} / \mathrm{mL}$ in of empagliflozin treatment patient with $\mathrm{AF}$ on cardiac physiology and metabolism in patients with heart failure

CTRI/2017/09/009734 Empagliflozin trial in Chronic symptomatic patients with chronic heart heart failure (NYHA class failure

Sample: NR

JPRN-jRCTs071180091 Phase: NS

Sample: NR for HFpEF with Type2

Previous myocardial infarction $\geq 6$ months ago, or previous coronary revascularization $\geq 2$ months ago

Symptoms 4 signs of heart failure (as defined in 2016 European society of cardiology guidelines) Of cardiology grade II/III

LVEF $\geq 50 \%$ as measured by $\mathrm{ECHO}$

II-IV)

LVEF $>40 \%$ Elevated NTproBNP > $300 \mathrm{pg} / \mathrm{mL}$ for patients without $A F, O R$

$>900 \mathrm{pg} / \mathrm{ml}$ for patients with AF

(NYHA class $\|-\| I$ )
Effect of empagliflozin DM A clinical study for cardioprotective effect of empagliflozin in T2DM patients with heart failure and exploring associated factors (EMPOWERMENT)
Prior

LVEF $<30 \%$ NYHA Class

IV or recent diastolic volume| LVEFIRegional LV ospitalization for diastolic function decompensated heart failure (HF)

Permanent atrial flutter or atrial fibrillation

Symptomatic heart failure NR

LVEF > 50\% BNP $\geq 35 \mathrm{pg} /$ $\mathrm{dL}$

Change from baseline in: 6MWD|LVMI|left atrial volume index $(\mathrm{LAVI})$ | average $\mathrm{E} / \mathrm{e}^{\prime}$ ratio| NT-proBNP minnesota living with heart failure questionnaire (MLHFQ) score

Change from baseline in myocardial phosphocreatine-to-ATP ratio
The composite endpoint: CV death or hospitalization for heart failure; All-cause mortality; Change from baseline in clinical summary score of the KCCQ; All-cause hospitalizations

Change from baseline in: uptake efficiency (Peak VO2) BNP LVEF and RVEF(by MRI) 


\section{Other SGLT2 inhibitors}

Limited evidence from small unpublished Japanese RCTs suggested that luseogliflozin (63 patients), and tofogliflozin (62 patients) improved diastolic dysfunction from baseline in adults with diabetes and $\mathrm{HFpEF}^{[71]}$. However, luseogliflozin, when compared with voglibose, did not improve diastolic dysfunction or brain natriuretic peptide (BNP) levels in type 2 diabetes patients with HFpEF ( defined as LVEF > 45\% and $\left.\mathrm{BNP}=35 \mathrm{pg} / \mathrm{mL}^{2}\right)^{[72]}$.

We identified 60 registered studies of ipragliflozin, sotagliflozin, luseogliflozin, or tofogliflozin that did not report enrolling patients with HFpEF.

\section{DISCUSSION}

Our review found insufficient evidence that SGLT2 inhibitors can improve cardiovascular mortality, morbidity or hospitalizations in patients with HFpEF. We found no studies that reported adverse effects from SGLT2 inhibitors specifically in adults with $\mathrm{HFpEF}^{[73]}$. Limited evidence of some improvement in intermediate outcomes of diastolic dysfunction lack clinical significance with valid prediction of better patient-centered outcomes and healthcare utilization required in future studies ${ }^{[74,75]}$. The absence of RCTs that met pooling criteria precluded planned meta-analyses. Previously published indirect net-work metaanalyses focused on intermediate outcomes of diastolic dysfunction regardless of baseline HFpEF and did not find consistent superiority of SGLT2 inhibitors when compared with placebo or other anti-diabetic medications ${ }^{[74,75]}$. Previously published direct meta-analysis concluded that SGLT2 inhibitors reduced the risk of cardiovascular death or heart-failure hospitalization regardless of baseline heart failure diagnosis ${ }^{[15]}$. However, this meta-analysis did not look at patient outcomes depending on baseline LVEF and specifically in patients with $\mathrm{HFpEF}^{[15]}$.

Various definitions of HFpEF preclude valid comparisons of patient outcomes among RCTs of the same SGLT2 inhibitor and across RCTs of different SGLT2 inhibitors [Supplementary Table 2] $]^{[28,33,34,37,76-80]}$. Ongoing studies use various inclusion and exclusion criterias with a potential threat to external validity of completed in future studies ${ }^{[81]}$. Consistent consensus definition of HFpEF in guidelines, RCTs, and real life clinical practice and coding is essential for valid assessment of the best treatment options in adults with $\mathrm{HFpEF}^{[35,82-85]}$. Patient outcomes can differ depending on HFpEF diagnostic criteria and should be assessed by HFpEF phenotypes ${ }^{[38,79,80]}$. Subgroup analyses by HFpEF diagnostic criteria and phenotypes should be conducted with prespecified evidence-based definitions, stratified randomization and adequate sample $\operatorname{size}^{[86,87]}$. Known interactions between HFpEF phenotypes and treatment effects should guide future studies aimed at efficacious treatments ${ }^{[1,83]}$. Registered protocols of ongoing RCTs are inconsistent in addressing recommendations by guidelines hard clinical outcomes including all-cause and cardiovascular mortality, morbidity, hospitalizations, or quality of life in people with $\mathrm{HFpEF}^{[88,89]}$. Such inconsistency indicates that the most important clinical questions regarding the benefits from SGLT2 inhibitors on patient centered outcomes may not be answered in the upcoming years.

Available heart failure guidelines recommend SGLT2 inhibitors to reduce cardiovascular mortality and hospitalizations in patients with diabetes [Supplementary Table 3 $]^{[5,26-28,89,90]}$. Some guidelines specify recommendations of SGLT2 inhibitors in heart failure with reduced ejection fraction ${ }^{[5,29]}$. Very few guidelines including the Canadian Cardiovascular Society and Canadian Heart Failure Society guidelines and the American Diabetes Association Standard of Care statement acknowledge uncertainty regarding potential benefits of SGLT2 inhibitors for patients with midrange or preserved $\operatorname{LVEF}^{[5,29]}$. Older guidelines do not make recommendations for or against SGLT2 inhibitors aimed at the prevention of heart failure hospitalizations or mortality ${ }^{[33,34,88,91]}$.

We found no large observational studies of SGLT2 inhibitors in HFpEF. We can speculate that inconsistencies in diagnostic and treatment recommendations for patients with HFpEF preclude optimal treatment choices 
in these patients ${ }^{[92,93]}$. Diabetes care should be provided by multidisciplinary teams of endocrinologists, cardiologists and nephrologists and include assessment of HFpEF and consequent decisions of the best treatment choices ${ }^{[5,694,95]}$.

Inconsistency in clinical research and practice policies, market approval, and coverage decisions across countries preclude universal patient access to the optimal treatment options ${ }^{[96-98]}$. Harmonization of health technology assessments methodology and data sharing across the countries would improve the quality of care in patients with heart failure and specifically $\mathrm{HFpEF}^{[99,100]}$. The International Network of Agencies for Health Technology Assessment calls for transparency in evidence collection, data sharing, and consistent evidence appraisal to improve patient outcomes across the globe ${ }^{[101]}$.

Our work has implications for future research. The emerging epidemic of diabetes, arterial hypertension and HFpEF requires international efforts in improving the quality of evidence and the quality of healthcare ${ }^{[10,26,40]}$. Professional associations and health technology assessment groups need to collaborate in the development of consensus definitions of HFpEF, in prospective design of high quality powered RCTs in adults with various phenotypes and underlying causes of HFpEF. Individual patient data meta-analyses of completed RCTs and registries of medical records can shed light on optimal treatment choices in adults with $\mathrm{HFpEF}^{[102-105]}$.

In conclusion, existing evidence is insufficient to support definitive clinical recommendations for use of SGLT2- Inhibitors in adults with HFpEF. Future research should employ consistent definitions of HFpEF and examine the effects from SGLT2- Inhibitors in patients with various HFpEF phenotypes and underlying causes.

\section{DECLARATIONS}

\section{Authors' contributions}

Designed review protocol, research questions and performed data analysis and interpretation: Shamliyan TA

Conceptualized study objectives and goals and contributed to data analysis and interpretation: Aronow WS Contributed to study design and execution, data analysis and interpretation: Avanesova AA

Made substantial contributions to the writing of the manuscript: Shamliyan TA, Avanesova AA, Aronow WS

\section{Availability of data and materials}

Not applicable.

\section{Financial support and sponsorship}

None.

\section{Conflicts of interest}

All authors declared that there are no conflicts of interest.

\section{Ethical approval and consent to participate}

Not applicable.

\section{Consent for publication}

Not applicable.

\section{Copyright}

(c) The Author(s) 2020. 


\section{REFERENCES}

1. Shamliyan T, Nambiar S, Martin A. PCV63 what's the cost of hospitalisations due to heart failure with preserved ejection fraction in the United States? Value Health 2019;22:S552-3.

2. Dhingra A, Garg A, Kaur S, et al. Epidemiology of heart failure with preserved ejection fraction. Curr Heart Fail Rep 2014;11:354-65.

3. Ziaeian B, Heidenreich PA, Xu H, et al. Race/ethnic differences in outcomes among hospitalized medicare patients with heart failure and preserved ejection fraction. JACC Heart Fail 2017;5:483-93.

4. Bouthoorn S, Valstar GB, Gohar A, et al. The prevalence of left ventricular diastolic dysfunction and heart failure with preserved ejection fraction in men and women with type 2 diabetes: a systematic review and meta-analysis. Diab Vasc Dis Res 2018;15:477-93.

5. American Diabetes Association Position Statement. Cardiovascular disease and risk management: standards of medical care in diabetes-2020. Diabetes Care 2020;43:S111-34.

6. American Diabetes Association Position Statement. 12. Older Adults: Standards of Medical Care in Diabetes-2020. Diabetes Care 2020;43:S152-62.

7. Rawshani A, Rawshani A, Franzen S, et al. Mortality and cardiovascular disease in type 1 and type 2 diabetes. $N$ Engl $J$ Med 2017;376:1407-18.

8. Htay T, Soe K, Lopez-Perez A, Doan AH, Romagosa MA, Aung K. Mortality and cardiovascular disease in type 1 and type 2 diabetes. Curr Cardiol Rep 2019;21:45.

9. Borlaug BA. Evaluation and management of heart failure with preserved ejection fraction. Nat Rev Cardiol 2020;17:559-73.

10. Oktay AA, Rich JD, Shah SJ. The emerging epidemic of heart failure with preserved ejection fraction. Curr Heart Fail Rep 2013;10:401-10.

11. Zheng SL, Chan FT, Nabeebaccus AA, et al. Drug treatment effects on outcomes in heart failure with preserved ejection fraction: a systematic review and meta-analysis. Heart (British Cardiac Society) 2018;104:407-15.

12. Kjeldsen SE, von Lueder TG, Smiseth OA, et al. Medical therapies for heart failure with preserved ejection fraction. Hypertension 2020;75:23-32.

13. Gladden JD, Chaanine AH, Redfield MM. Heart failure with preserved ejection fraction. Ann Rev Med 2018;69:65-79.

14. Bonsu KO, Arunmanakul P, Chaiyakunapruk N. Pharmacological treatments for heart failure with preserved ejection fraction-a systematic review and indirect comparison. Heart Fail Rev 2018;23:147-56.

15. Zelniker TA, Wiviott SD, Raz I, et al. SGLT2 inhibitors for primary and secondary prevention of cardiovascular and renal outcomes in type 2 diabetes: a systematic review and meta-analysis of cardiovascular outcome trials. Lancet (London, England) 2019;393:31-9.

16. Birkeland KI, Jorgensen ME, Carstensen B, et al. Cardiovascular mortality and morbidity in patients with type 2 diabetes following initiation of sodium-glucose co-transporter-2 inhibitors versus other glucose-lowering drugs (CVD-REAL Nordic): a multinational observational analysis. Lancet Diabetes Endocrinol 2017;5:709-17.

17. Zelniker TA, Braunwald E. Cardiac and renal effects of sodium-glucose co-transporter 2 inhibitors in diabetes: JACC state-of-the-art review. J Am Coll Cardiol 2018;72:1845-55.

18. Singh AK, Singh R. Heart failure hospitalization with SGLT-2 inhibitors: a systematic review and meta-analysis of randomized controlled and observational studies. Expert Rev Clin Pharmacol 2019;12:299-308.

19. Lan NSR, Fegan PG, Yeap BB, Dwivedi G. The effects of sodium-glucose cotransporter 2 inhibitors on left ventricular function: current evidence and future directions. ESC Heart Fail 2019;6:927-35.

20. AstraZeneca Pharmaceuticals LP Wilmington D. FARXIGA- dapagliflozin tablet, film coated FDA label. May 2020. Available from: https://nctr-crs.fda.gov/fdalabel/services/spl/set-ids/01 f90c94-71cb-4a1f-81ff-8004b850529b/spl-doc?hl=dapagliflozin. [Last accessed on 16 Nov 2020]

21. Boehringer Ingelheim Pharmaceuticals Inc. JARDIANCE- empagliflozin tablet, film coated FDA label. 2014. Available from: https:// nctr-crs.fda.gov/fdalabel/services/spl/set-ids/a77214ca-572e-485e-aae9-f7950187e5fb/spl-doc?hl=empagliflozin. [Last accessed on 16 Nov 2020]

22. Janssen Pharmaceuticals Inc. INVOKANA- canagliflozin tablet, film coated FDA label. March 2013. Available from: https://nctr-crs.fda. gov/fdalabel/services/spl/set-ids/b9057d3b-b104-4f09-8a61-c61ef9d4a3f3/spl-doc?hl=canagliflozin. [Last accessed on 16 Nov 2020]

23. Fitchett D, Inzucchi SE, Cannon CP, et al. Empagliflozin reduced mortality and hospitalization for heart failure across the spectrum of cardiovascular risk in the EMPA-REG outcome trial. Circulation 2019;139:1384-95.

24. Radholm K, Figtree G, Perkovic V, et al. Canagliflozin and heart failure in type 2 diabetes mellitus: results from the CANVAS program. Circulation 2018;138:458-68.

25. Dewan P, Solomon SD, Jhund PS, et al. Efficacy and safety of sodium-glucose co-transporter 2 inhibition according to left ventricular ejection fraction in DAPA-HF. Eur J Heart Fail 2020;22:1247-58.

26. Dunlay SM, Givertz MM, Aguilar D, et al. Type 2 diabetes mellitus and heart failure: a scientific statement from the American heart association and the heart failure society of America: this statement does not represent an update of the 2017 ACC/AHA/HFSA heart failure guideline update. Circulation 2019;140:e294-324.

27. Dunlay SM, Givertz MM, Aguilar D, et al. Type 2 diabetes mellitus and heart failure: a scientific statement from the American heart association and the heart failure society of America. J Card Fail 2019;25:584-619.

28. Ezekowitz JA, O’Meara E, McDonald MA, et al. 2017 comprehensive update of the canadian cardiovascular society guidelines for the management of heart failure. Can J Cardiol 2017;33:1342-433.

29. O'Meara $\mathrm{E}, \mathrm{McD}$ onald $\mathrm{M}, \mathrm{Chan} \mathrm{M}$, et al. CCS/CHFS heart failure guidelines: clinical trial update on functional mitral regurgitation, 
SGLT2 inhibitors, ARNI in HFpEF, and tafamidis in amyloidosis. Can J Cardiol 2020;36:159-69.

30. Higgins J, Green S, editors. Cochrane handbook for systematic reviews of interventions. Version 5.1.0. London: The Cochrane Collaboration; 2011. Available from: https://training.cochrane.org/handbook/current. [Last accessed on 16 Nov 2020]

31. Slutsky J, Atkins D, Chang S, Sharp BA. AHRQ series paper 1: comparing medical interventions: AHRQ and the effective health-care program. J Clin Epidemiol 2010;63:481-3.

32. Polisena J, Garritty C, Kamel C, Stevens A, Abou-Setta AM. Rapid review programs to support health care and policy decision making: a descriptive analysis of processes and methods. Syst Rev 2015;4:1-7.

33. Writing Committee M, Yancy CW, Jessup M, et al. 2013 ACCF/AHA guideline for the management of heart failure: a report of the American college of cardiology foundation/American heart association task force on practice guidelines. Circulation 2013;128:e240-327.

34. Ponikowski P, Voors AA, Anker SD, et al. 2016 ESC Guidelines for the diagnosis and treatment of acute and chronic heart failure: the task force for the diagnosis and treatment of acute and chronic heart failure of the European Society of Cardiology (ESC)Developed with the special contribution of the Heart Failure Association (HFA) of the ESC. Eur Heart J 2016;37:2129-200.

35. Chow B, Rabkin SW. The relationship between arterial stiffness and heart failure with preserved ejection fraction: a systemic metaanalysis. Heart Fail Rev 2015;20:291-303.

36. Machino-Ohtsuka T, Seo Y, Ishizu T, et al. Clinical utility of the 2016 ASE/EACVI recommendations for the evaluation of left ventricular diastolic function in the stratification of post-discharge prognosis in patients with acute heart failure. Eur heart J Cardiovasc Imaging 2019;20:1129-37.

37. Nagueh SF, Smiseth OA, Appleton CP, et al. Recommendations for the evaluation of left ventricular diastolic function by echocardiography: an update from the American society of echocardiography and the European association of cardiovascular imaging. $J$ Am Soc Echocardiogr 2016;29:277-314.

38. Lindman BR, Davila-Roman VG, Mann DL, et al. Cardiovascular phenotype in HFpEF patients with or without diabetes: a RELAX trial ancillary study. J Am Coll Cardiol 2014;64:541-9.

39. Greene SJ, Mentz RJ, Fiuzat M, et al. Reassessing the role of surrogate end points in drug development for heart failure. Circulation 2018;138:1039-53.

40. Lekavich CL, Barksdale DJ, Neelon V, Wu JR. Heart failure preserved ejection fraction (HFpEF): an integrated and strategic review. Heart Fail Rev 2015;20:643-53.

41. Zinman B, Inzucchi SE, Lachin JM, et al. Rationale, design, and baseline characteristics of a randomized, placebo-controlled cardiovascular outcome trial of empagliflozin (EMPA-REG OUTCOME). Cardiovasc Diabetol 2014;13:102.

42. Wiviott SD, Raz I, Bonaca MP, et al. The design and rationale for the dapagliflozin effect on cardiovascular events (DECLARE)-TIMI 58 Trial. Am Heart J 2018;200:83-9.

43. Ridderstrale M, Svaerd R, Zeller C, Kim G, Woerle HJ, Broedl UC. Rationale, design and baseline characteristics of a 4-year (208-week) phase III trial of empagliflozin, an SGLT2 inhibitor, versus glimepiride as add-on to metformin in patients with type 2 diabetes mellitus with insufficient glycemic control. Cardiovasc Diabetol 2013;12:129.

44. Neal B, Perkovic V, de Zeeuw D, et al. Rationale, design, and baseline characteristics of the Canagliflozin Cardiovascular Assessment Study (CANVAS)--a randomized placebo-controlled trial. Am Heart J 2013;166:217-23.e11.

45. Abraham WT, Ponikowski P, Brueckmann M, et al. Rationale and design of the EMPERIAL-preserved and EMPERIAL-reduced trials of empagliflozin in patients with chronic heart failure. Eur J Heart Fail 2019;21:932-42.

46. Fu R, Gartlehner G, Grant M, et al. Conducting quantitative synthesis when comparing medical interventions: AHRQ and the effective health care program. J Clin Epidemiol 2011;64:1187-97.

47. Levine M, Ensom MH. Post hoc power analysis: an idea whose time has passed? Pharmacotherapy 2001;21:405-9.

48. Goodman SN, Berlin JA. The use of predicted confidence intervals when planning experiments and the misuse of power when interpreting results. Ann Intern Med 1994;121:200-6.

49. Yuan KH, Maxwell S. On the post hoc power in testing mean differences. J Educ Behav Stat 2005;30:141-67.

50. Agency for Healthcare Research and Quality. Methods Guide for Effectiveness and Comparative Effectiveness Reviews. AHRQ Publication No 10(14)-EHC063-EF. 2014. Rockville, MD. Available from: https://effectivehealthcare.ahrq.gov/index.cfm/search-forguides-reviews-and-reports/?pageaction=displayproduct\&productid=318. [Last accessed on 16 Nov 2020]

51. Guyatt GH, Oxman AD, Kunz R, et al. GRADE guidelines 6. Rating the quality of evidence--imprecision. J Clin Epidemiol 2011;64:1283-93.

52. Viswanathan M, Berkman ND, Dryden DM, Hartling L. Assessing risk of bias and confounding in observational studies of interventions or exposures: further development of the RTI item bank. Rockville (MD): Agency for Healthcare Research and Quality (US); 2013.

53. Higgins JP, Altman DG, Gotzsche PC, et al. The cochrane collaboration's tool for assessing risk of bias in randomised trials. $B M J$ 2011;343:d5928.

54. Sterne JA, Hernán MA, Reeves BC, et al. ROBINS-I: a tool for assessing risk of bias in non-randomised studies of interventions. $B M J$ $2016 ; 355$.

55. Grading of Recommendations Assessment Development and Evaluation (GRADE) Workgin Group. GRADE Handbook. Available from: http://gdt.guidelinedevelopment.org/central_prod/_design/client/handbook/handbook.html\#h.fueh5iz0cor4. [Last accessed on 16 Nov 2020]

56. Guyatt GH, Oxman AD, Sultan S, et al. GRADE guidelines: 9. Rating up the quality of evidence. J Clin Epidemiol 2011;64:1311-6.

57. Figtree GA, Radholm K, Barrett TD, et al. Effects of canagliflozin on heart failure outcomes associated with preserved and reduced ejection fraction in type 2 diabetes mellitus. Circulation 2019;139:2591-3. 
58. Kato ET, Silverman MG, Mosenzon O, et al. Effect of dapagliflozin on heart failure and mortality in type 2 diabetes mellitus. Circulation 2019;139:2528-36.

59. Ponikowski P. Abraham W. Favourable effects of empagliflozin on congestion, diuretic use and all-cause healthcare resource utilisation in the EMPERIAL trials. European Society of Cardiology 365. 2020; HFA Discoveries. Available from: https://esc365.escardio.org/ Congress/223730-favourable-effects-of-empagliflozin-on-congestion-diuretic-use-and-all-cause-healthcare-resource-utilisation-in-theemperial-trials. [Last accessed on 16 Nov 2020]

60. Lindenfeld J. Patient-reported outcomes with empagliflozin in the EMPERIAL trials. European Society of Cardiology 365. 2020; HFA Discoveries. Available from: https://esc365.escardio.org/Congress/223722-patient-reported-outcomes-with-empagliflozin-in-the-emperialtrials. [Last accessed on 16 Nov 2020]

61. Boehringer Ingelheim. Boehringer Ingelheim and Lilly provide update on Jardiance ${ }^{\circledR}$ phase III exercise ability studies in chronic heart failure. 2019. Available from: https://wwwboehringer-ingelheimus/press-release/boehringer-ingelheim-and-lilly-provide-update-jardiancephase-iii-exercise-ability. [Last accessed on 16 Nov 2020]

62. Cosentino F, Cannon CP, Cherney DZI, et al. Efficacy of ertugliflozin on heart failure-related events in patients with type 2 diabetes mellitus and established atherosclerotic cardiovascular disease: results of the VERTIS CV trial. Circulation 2020; doi: 10.1161/ CIRCULATIONAHA.120.050255.

63. Mahaffey KW, Neal B, Perkovic V, et al. Canagliflozin for primary and secondary prevention of cardiovascular events: results from the CANVAS program (Canagliflozin Cardiovascular Assessment Study). Circulation 2018;137:323-34.

64. Matsutani D, Sakamoto M, Kayama Y, Takeda N, Horiuchi R, Utsunomiya K. Effect of canagliflozin on left ventricular diastolic function in patients with type 2 diabetes. Cardiovasc Diabetol 2018;17:73.

65. Sezai A, Sekino H, Unosawa S, Taoka M, Osaka S, Tanaka M. Canagliflozin for Japanese patients with chronic heart failure and type II diabetes. Cardiovasc Diabetol 2019;18:76.

66. Singh JS, Fathi A, Vickneson K, et al. Research into the effect of sodium-glucose linked transporter inhibition in left ventricular remodelling in patients with heart failure and diabetes mellitus. Eur Heart J 2018;Supplement 1(P905): American Diabetes Association meeting, Orlando. Available from: https://esc365.escardio.org/Congress/ESC-Congress-2018/Poster-Session-1-Chronic-heart-failureTreatment/177516-research-into-the-effect-of-sodium-glucose-linked-transporter-inhibition-in-left-ventricular-remodelling-in-patientswith-heart-failure-and-diabetes-mellitus. [Last accessed on 16 Nov 2020]

67. Bonora BM, Vigili de Kreutzenberg S, Avogaro A, Fadini GP. Effects of the SGLT2 inhibitor dapagliflozin on cardiac function evaluated by impedance cardiography in patients with type 2 diabetes. Secondary analysis of a randomized placebo-controlled trial. Cardiovasc Diabetol 2019;18:106.

68. Verma S, Garg A, Yan AT, et al. Effect of empagliflozin on left ventricular mass and diastolic function in individuals with diabetes: an important clue to the EMPA-REG outcome trial? Diabetes Care 2016;39:e212-3.

69. Cannon CP, McGuire DK, Pratley R, et al. Design and baseline characteristics of the eValuation of ERTugliflozin efflcacy and safety cardiovascular outcomes trial (VERTIS-CV). Am Heart J 2018;206:11-23.

70. Cannon CP, Pratley R, Dagogo-Jack S, et al. Cardiovascular outcomes with ertugliflozin in type 2 diabetes. New Engl J Med 2020;383:1425-35.

71. Sakai T, Miura S. Abstract 17041: effect of sodium-glucose cotransporter 2 inhibitor on vascular endothelial function and diastolic function in patients with heart failure with preserved ejection fraction (hfpef). Circulation 2017;136:A17041. Available from: https:// www.ahajournals.org/doi/10.1161/circ.136.suppl_1.17041. [Last accessed on 16 Nov 2020]

72. Ejiri K, Miyoshi T, Kihara H, Hata Y, Nagano T, et al. Drug effect of luseogliflozin and voglibose on heart failure with preserved ejection fraction in diabetic patients: a multicenter randomized-controlled trial. ESC Congress 2019. Available from: https://esc365.escardio.org/ Congress/ESC-CONGRESS-2019/New-treatment-studies-in-heart-failure/196088-drug-effect-of-luseogliflozin-and-voglibose-on-heartfailure-with-preserved-ejection-fraction-in-diabetic-patients-a-multicenter-randomized-controlled-trial\#abstract(Abstract: 1407). [Last accessed on 16 Nov 2020]

73. U.S. Food and Drug Administration. Sodium-glucose Cotransporter-2 (SGLT2) Inhibitors. Postmarket Drug Safety Information for Patients and Providers 2020. Available from: https://www.fda.gov/drugs/postmarket-drug-safety-information-patients-and-providers/ sodium-glucose-cotransporter-2-sglt2-inhibitors. [Last accessed on 16 Nov 2020]

74. Ida S, Kaneko R, Imataka K, et al. Effects of oral antidiabetic drugs and glucagon-like peptide-1 receptor agonists on left ventricular diastolic function in patients with type 2 diabetes mellitus: a systematic review and network meta-analysis. Heart Fail Rev 2020; doi: 10.1007/s10741-020-09936-w.

75. Zhang DP, Xu L, Wang LF, Wang HJ, Jiang F. Effects of antidiabetic drugs on left ventricular function/dysfunction: a systematic review and network meta-analysis. Cardiovasc Diabetol 2020;19:10.

76. Expert Panel on Cardiac Imaging, White RD, Kirsch J, Bolen MA, Batlle JC, Brown RKJ, et al. ACR Appropriateness Criteria((R)) Suspected New-Onset and Known Nonacute Heart Failure. J Am Coll Radiol 2018;15:S418-31.

77. Pieske B, Tschope C, de Boer RA, et al. How to diagnose heart failure with preserved ejection fraction: the HFA-PEFF diagnostic algorithm: a consensus recommendation from the Heart Failure Association (HFA) of the European Society of Cardiology (ESC). Eur heart J 2019;40:3297-317.

78. Reddy YNV, Carter RE, Obokata M, Redfield MM, Borlaug BA. A simple, evidence-based approach to help guide diagnosis of heart failure with preserved ejection fraction. Circulation 2018;138:861-70.

79. Reddy YNV, Borlaug BA. Response by reddy and borlaug to letters regarding article, "a simple, evidence-based approach to help guide diagnosis of heart failure with preserved ejection fraction". Circulation 2019;139:992-3. 
80. Obokata M, Reddy YNV, Borlaug BA. Diastolic dysfunction and heart failure with preserved ejection fraction: understanding mechanisms by using noninvasive methods. JACC Cardiovasc Imaging 2020;13:245-57.

81. Wittbrodt ET, Eudicone JM, Bell KF, Enhoffer DM, Latham K, Green JB. Eligibility varies among the 4 sodium-glucose cotransporter-2 inhibitor cardiovascular outcomes trials: implications for the general type 2 diabetes US population. Am J Manag Care 2018;24:S138-45.

82. Chetrit M, Cremer PC, Klein AL. Imaging of diastolic dysfunction in community-based epidemiological studies and randomized controlled trials of HFpEF. JACC Cardiovasc Imaging 2020;13:310-26.

83. Ho JE, Zern EK, Wooster L, et al. Differential clinical profiles, exercise responses, and outcomes associated with existing HFpEF definitions. Circulation 2019;140:353-65.

84. Oh JK, Miranda WR, Bird JG, Kane GC, Nagueh SF. The 2016 diastolic function guideline: is it already time to revisit or revise them? JACC Cardiovasc Imaging 2020;13:327-35.

85. van der Meer P, Gaggin HK, Dec GW. ACC/AHA versus ESC Guidelines on Heart Failure: JACC Guideline Comparison. $J$ Am Coll Cardiol 2019;73:2756-68.

86. Wallach JD, Sullivan PG, Trepanowski JF, Sainani KL, Steyerberg EW, Ioannidis JP. Evaluation of evidence of statistical support and corroboration of subgroup claims in randomized clinical trials. JAMA Int Med 2017;177:554-60.

87. Brookes ST, Whitley E, Peters TJ, Mulheran PA, Egger M, Davey Smith G. Subgroup analyses in randomised controlled trials: quantifying the risks of false-positives and false-negatives. Health Technol Assess 2001;5:1-56.

88. Yancy CW, Jessup M, Bozkurt B, et al. 2017 ACC/AHA/HFSA Focused Update of the 2013 ACCF/AHA guideline for the management of heart failure: a report of the American college of cardiology/american heart association task force on clinical practice guidelines and the heart failure society of America. J Cardiac Fail 2017;23:628-51.

89. Das SR, Everett BM, Birtcher KK, et al. 2020 expert consensus decision pathway on novel therapies for cardiovascular risk reduction in patients with type 2 diabetes: a report of the american college of cardiology solution set oversight committee. J Am Coll Cardiol 2020;76:1117-45.

90. Seferovic PM, Coats AJS, Ponikowski P, et al. European society of cardiology/heart failure association position paper on the role and safety of new glucose-lowering drugs in patients with heart failure. Eur J Heart Fail 2020;22:196-213.

91. Writing Committee M, Yancy CW, Jessup M, et al. 2016 ACC/AHA/HFSA focused update on new pharmacological therapy for heart failure: an update of the 2013 ACCF/AHA guideline for the management of heart failure: a report of the American college of cardiology/american heart association task force on clinical practice guidelines and the heart failure society of America. Circulation 2016;134:e282-93.

92. Gunawan F, Nassif ME, Partridge C, Ahmad T, Kosiborod M, Inzucchi SE. Relative frequency of cardiology vs. endocrinology visits by type 2 diabetes patients with cardiovascular disease in the USA: implications for implementing evidence-based use of glucose-lowering medications. Cardiovasc Endocrinol Metab 2020;9:56-9.

93. Zoler ML. SGLT2 Inhibitors, developed for T2D, now 'belong to cardiologists and nephrologists. MedScape. 2020; Medscape Medical News: Conference News: ADA 2020. Available from: https://www.medscape.com/viewarticle/934107. [Last accessed on 16 Nov 2020]

94. American Diabetes Association Position Statement 10. Cardiovascular disease and risk management: standards of medical care in diabetes - 2020. Diabetes Care 2020;43:S111-34.

95. American Diabetes Association Position Statement 4. Comprehensive Medical Evaluation and Assessment of Comorbidities: Standards of Medical Care in Diabetes - 2020. Diabetes Care 2020;43:S37-47.

96. International Working Group for HTAA Advancement, Neumann PJ, Drummond MF, Jonsson B, Luce BR, Schwartz JS, et al. Are key principles for improved health technology assessment supported and used by health technology assessment organizations? Int $J$ Technol Assess Health Care 2010;26:71-8.

97. Kristensen FB, Lampe K, Chase DL, et al. Practical tools and methods for health technology assessment in Europe: structures, methodologies, and tools developed by the European Network for Health Technology Assessment, EUnetHTA. Int J Technol Assess Health Care 2009;25:1-8.

98. World Health Organization. 2015 Global Survey on Health Technology Assessment by National Authorities. ISBN 9789241509749. 2015. Available from: https://www.who.int/health-technology-assessment/MD_HTA_oct2015_final_web2.pdf?ua=1. [Last accessed on 16 Nov 2020]

99. Fanourgiakis J, Kanoupakis E. Health technology assessment (HTA): a brief introduction of history and the current status in the field of cardiology under the economic crisis. J Evid Based Med 2015;8:161-4.

100. Elbarbary M. Health technology assessment (HTA) in cardiac field. J Saudi Heart Assoc 2010;22:77-84.

101. The International Network of Agencies for Health Technology Assessment. The Uniquiness of INAHTA INAHTA Position Statement. 2020. Available from: https://www.inahta.org/position-statements/. [Last accessed on 16 Nov 2020]

102. Yaku H, Ozasa N, Morimoto T, et al. Demographics, management, and in-hospital outcome of hospitalized acute heart failure syndrome patients in contemporary real clinical practice in Japan- observations from the prospective, multicenter kyoto congestive heart failure (KCHF) registry. Circ J 2018;82:2811-9.

103. Parissis J, Farmakis D, Triposkiadis F. Heart failure registries: how far can we go? Euro J Heart Fail 2016;18:626-8.

104. Bassand JP, Apenteng PN, Atar D, et al. GARFIELD-AF: a worldwide prospective registry of patients with atrial fibrillation at risk of stroke. Future Cardiol 2020; doi: 10.2217/fca-2020-0014.

105. Alhabib KF, Gamra H, Almahmeed W, et al. Acute myocardial infarction and acute heart failure in the Middle East and North Africa: study design and pilot phase study results from the PEACE MENA registry. PLoS One 2020;15:e0236292. 